\title{
Analysis of driver behavior in Amman using Manchester Driver Behavior Questionnaire
}

\author{
K. Jadaan ${ }^{1}$, N. Albeetar ${ }^{2, *}$, D. Abuhalimeh ${ }^{3}$, Y. Naji ${ }^{4}$ \\ ${ }^{1}$ University of Jordan, Department of Civil Engineering \\ Amman, 11942, Jordan \\ ${ }^{2}$ Bitar Consultants, Department of Civil Engineering \\ Amman, 11196, Jordan \\ ${ }^{3}$ Collaboration Management \& Control Solutions, Department of Civil \\ Engineering \\ Amman, 11180, Jordan \\ ${ }^{4}$ Arab Business Corporation, Department of Civil Engineering \\ Amman, 11942, Jordan \\ "e-mail: bitarnoor96@gmail.com
}

Submitted: 23/02/2021; Accepted: 21/04/2021; Published online: 30/04/2021

Abstract: A key component in combating traffic accidents is to study the contributory factors behind them, among these factors, the driver behavior stands out as the main causative factor. One of the most effective tools used worldwide in measuring self-reported driving components is the Manchester Driver Behavior Questionnaire (DBQ), it investigates the relationship between the driver and accidents involvement, throughout the analysis of both sociodemographic characteristics of drivers, and the risky driving components practiced such as; violations, errors and lapses. The present study investigates the factor structure of the DBQ and examines the relationships between the driver behavior factors and accident involvement. A survey questionnaire including the DBQ and background information was filled by a randomly selected sample of drivers in Amman, the capital of Jordan and the Statistical Package for Social Sciences (SPSS) software was used for data analysis. Driver behavior differed according to the gender, educational level and driving experience of the respondents. The results reflected the lifestyle, way of thinking and the general attitude of the driver and its relationship with traffic safety. 
Keywords: driver behavior; Manchester Driver Behavior Questionnaire; traffic safety; Jordan

\section{Introduction}

Road Traffic Accidents (RTA) may cause severe physical losses and disabilities, hold back economic growth especially in developing countries and affect the country's Gross Domestic Product (GDP) negatively. In fact, RTAs cost most countries about $2-3 \%$ of their GDP. Traffic accidents are increasingly being recognized as a major cause of death and a growing health problem, Significant part of the road traffic accidents are originated in inappropriately selected speeds or specifically to speeding [1]. Accident issues can be recognized: approximately 1.3 million crashes annually lead to nearly 40,000 fatalities and more than 1 million injuries [2].

Manchester DBQ (Driver Behavior Questionnaire) was used to measure the aberrant driving behaviors leading to accidents [3]. Hence, driver behavior is regarded by researchers as the main contributor to RTAs. Furthermore, Human factors in driving can be seen as being composed of two separate components, driving style and driving skills [4]. The effect of specific aspects of driver characteristics and behavior on accident occurrence were investigated.

In Jordan, RTA are considered as a serious problem with an estimated yearly cost of about $\$ 500$ million (about $2.5 \%$ of the country's GDP). This cost has increased $7.4 \%$ in the past five years [4]. According to the Jordan Traffic Institute (JTI), RTAs resulted in 571 deaths and 16203 injuries in 2018, and driver is the main contributor to the causation of RTAs (about $98 \%$ of total contributors). As such, a recommended road safety strategy was developed that focused on the role of driver characteristics and behavior [5]. A most recent study investigated the driver behavior relative to drivers' gender, while the current study measures the accident involvement in accordance with different driver characteristics studied in the questionnaire [6].

Manchester Driver Behavior Questionnaire (DBQ) is one of the commonly used tools in traffic psychology for measuring self-reported driving style and investigating the relationship between driving behavior and accident involvement. [7]

DBQ contains three subscales to capture different aspects of driver behavior; violations, errors and lapses [8]. Violations are defined as the behaviors which endanger traffic safety [9], such as driving under the influence of alcohol or drugs and tailgating the car in front. In particular, violations have been reported to be associated with active loss-of-control as well as with speeding and parking offences [10]. Errors are breaches of the rules, such as not noticing pedestrians on road and 
braking too hard, they seemed to be the main predictor of accident involvement among elderly drivers [11]. Furthermore, lapses are a set of problems related to the lack of attention and memory defects that cause embarrassment [9], lapses of concentration, for example; forgetting where you parked the car and switching on the wipers when you meant to switch on the lights.

The current study aims to explore specific aspects of driving behavior in Jordan and to investigate the reoccurrence of committing violations, errors, and lapses of the DBQ among Jordanian drivers. The results could be used as a reference in further studies to develop a country specific "Jordanian DBQ" which will help in controlling the driver aberrant behaviors that lead to accidents.

\section{Methodology}

\subsection{Sample}

A survey was conducted in Amman city, the capital of Jordan, through direct interviews with a total of randomly selected 200 drivers aged 22 years and above. Only 134 drivers (94 males and 40 females) agreed to participate in the survey and were asked to fill the DBQ.

\subsection{Measures}

The DBQ contains three subscales to capture different aspects of driver behavior; violations, errors and lapses. DBQ with extended violations was used to measure aberrant driver behaviors. The DBQ includes 10 items of ordinary violations, 8 items of lapses, and 8 items of errors It has 26 behaviors on a six-point scale $(0=$ never, $1=$ hardly ever, $2=$ occasionally, $3=$ quite often, $4=$ frequently, and $5=$ nearly all the time) The research assistants asked the participants to indicate how often they have committed every behavior.

\subsection{Demographic variables}

The participants were also asked to indicate their demographic information, age, gender, marital status, educational level, occupation, place of living, housing conditions, and other data related to their driving experience, such as the type of car, whether or not they use the seatbelt and why, their usual driving speed, number of miles their cars recorded and the history of accidents and injuries.

\subsection{Statistical analysis}

The Statistical Package for Social Sciences "IBM SPSS" was used to analyze the collected data. Descriptive statistics tools and central tendency measures, mean, 
median, mode and distribution measures (standard deviation) were also used to get further useful information.

\section{Results}

\subsection{Socio-demographic characteristics and accidents involvement}

Analysis of the socio-demographic characteristics of the participants showed that their age distribution ranged between 22 and 74 years with a mean age of 27.5 years. Most of the participants were males aged between 22-29 years (69 of the respondents). Moreover, $49 \%$ of participants had 2-5 years of driving experience, with a mean mileage of $45,678.65 \mathrm{~km}$.

Seat belt usage spots light on the driving attitude; $55 \%$ of drivers admitted that they don't use seatbelt, and $79.5 \%$ of them reported that it causes discomfort and restricts their movement.

When relating seatbelt usage with gender, $75 \%$ of female drivers reported that they always use the seatbelt. On the other hand, only $33 \%$ of male drivers use seatbelt. Hence, this result assures the finding of the paper "Role of gender and driver behavior in road traffic crashes" [5], which reported that typically, male participants were less likely to wear seat belts.

Table 1 shows age groups of the participants, and whether or not they had an accident. $51 \%$ of the participants below 30 years of age were involved in an accident, while the percentages of drivers who experienced a car accident in the age groups 30-39 years, 40-49 years, and above 50 years were 60\%, 83\%, and $100 \%$ respectively. These results indicate that accident involvement increases with age of drivers.

Table 1. Age group and accident involvement

\begin{tabular}{ccc}
\hline Age group & Accident involvement & Not involved \\
\hline$<30$ years & $51 \%(52)$ & $49 \%(51)$ \\
$30-39$ & $60 \%(12)$ & $40 \%(8)$ \\
$40-49$ & $83 \%(5)$ & $17 \%(1)$ \\
$>=50$ & $100 \%(5)$ & $0 \%(0)$ \\
\hline
\end{tabular}


Table 2 shows that $47 \%$ of female drivers were involved in traffic accidents, whereas the corresponding percentage of males was $55 \%$.

Table 2. Gender and accident involvement

\begin{tabular}{ccc}
\hline Gender & Accident involvement & Not involved \\
\hline Female & $47 \%(19)$ & $53 \%(21)$ \\
Male & $55 \%(52)$ & $45 \%(42)$ \\
\hline
\end{tabular}

Comparing these results with the results found in "Role of gender and driver behavior in road traffic crashes" [5], female drivers were less likely to be involved in traffic accidents.

Table 3 shows the relationship between the educational level of participating drivers and accident involvement. Surprisingly, the highest group involved in accidents was the one of drivers holding university degree (most educated, 54\%) compared with $46 \%$ of people with secondary school qualification. for drivers with an intermediate school educational level the number of drivers in the sample was not sufficient to derive conclusive result. These findings show that educational level is not related to the skills the driver needs to avoid being involved in an accident.

Table 3. Educational level and accident involvement

\begin{tabular}{ccc}
\hline Educational level & Accident involvement & Not involved \\
\hline University & $54 \%(64)$ & $46 \%(55)$ \\
Secondary & $46 \%(6)$ & $54 \%(7)$ \\
Intermediate & $50 \%(1)$ & $50 \%(1)$ \\
\hline
\end{tabular}

The effect of driving experience on accident involvement is represented in Table 4, It can be seen that drivers who have been driving for a longer period of time appear to commit higher cumulative number of accidents mainly due to their longer exposure to accident risk, thus increasing their probability of accident involvement.

Table 4. Driving experience and Accident involvement

\begin{tabular}{ccc}
\hline Driving experience & Accident involvement & Not involved \\
\hline Below 2 years & $20 \%(3)$ & $80 \%(12)$ \\
2-5 years & $53 \%(35)$ & $47 \%(31)$ \\
$5-10$ years & $54 \%(19)$ & $46 \%(16)$
\end{tabular}


More than 10 years

The results that link seatbelt usage and accident involvement aren't directly correlated, due to the fact that seatbelt usage reduces traffic fatalities and serious injuries, yet it doesn't prevent the accident from happening. As shown in Table 5, $22 \%$ of drivers who don't use seatbelt were seriously injured compared to $9 \%$ of those who use it.

Table 5. Seat belt usage and injuries

\begin{tabular}{cccc}
\hline \multicolumn{2}{c}{ Seatbelt use } & Accident involvement & Were injured \\
\hline \multirow{2}{*}{ Yes } & \multirow{2}{*}{$45 \%$} & Yes (55\%) & $9 \%$ \\
\cline { 3 - 4 } & \multirow{2}{*}{ No } & N5\% (45\%) & - \\
\cline { 3 - 4 } & & Yes (51\%) & $22 \%$ \\
\hline
\end{tabular}

\subsection{Causes of accidents}

The main contributing cause of accidents reported by drivers who were previously involved in an accident is careless driving (46.5\%), followed by excessive speeding $(19.7 \%)$, alcohol and drugs (7\%). Furthermore, $25.4 \%$ of the participants reported their involvement in traffic violations as an accident cause (Fig.1)

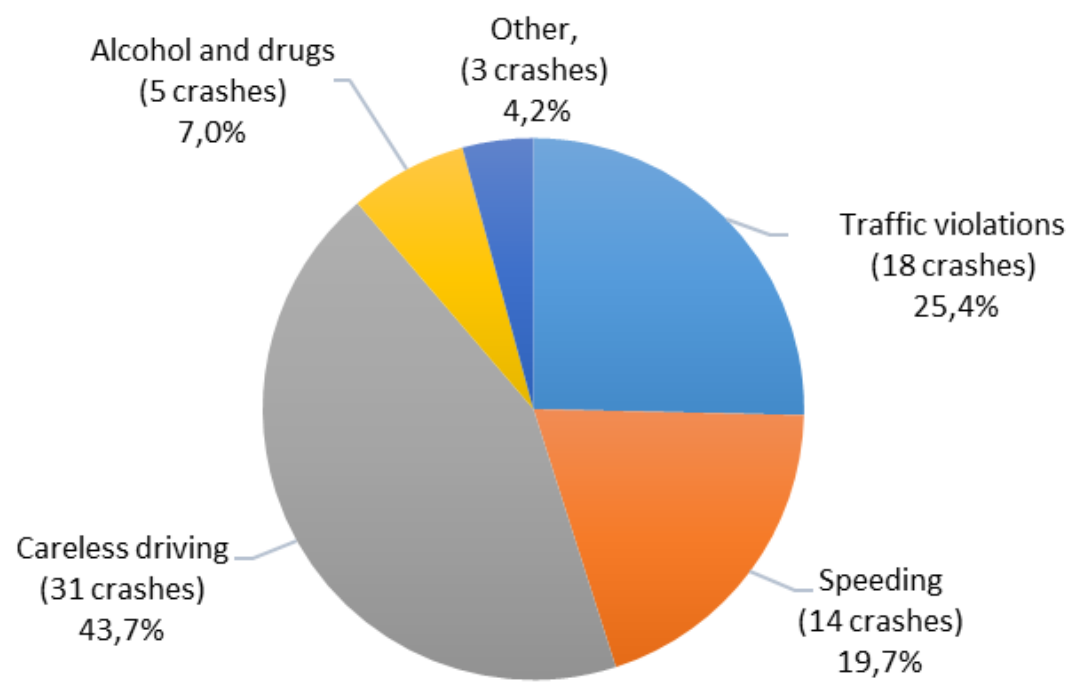

Figure 1. Causes of crashes among the surveyed drivers in Jordan 


\subsection{Violations, errors and lapses}

Traffic violations occur when drivers violate laws that regulate vehicle operation on streets and highways. These may vary depending on the country and area.

In Jordan the most common traffic violation is speeding, with $34 \%$ of people reporting this, when $30 \%$ of drivers reported that they disregard the speed limits late at night and early in the morning, and they also tend to disregard speed limits on main roads. Moreover, $29 \%$ of drivers become impatient with slow drivers in the outer lane and overtake on the inside lane (right lane). On the other hand, running a red light and getting involved in unofficial races with other drivers are the least violations committed, with the percentage of $7 \%$ and $11 \%$ respectively of the recorded sample.

After analyzing the violations measured in the DBQ, it turned out that they were divided into two main categories, the first one was violations of traffic regulations, and the other one was the violations related to other road users. Drivers in Amman tend to violate traffic regulations more than violations related to other road users

The errors, are typically misjudgments and failures of observation that may be hazardous to others. Such as attempting to overtake someone that you hadn't noticed to be signaling a left turn, failing to check the rear mirror before pulling out or changing lanes and under estimating the speed of an oncoming vehicle when overtaking, these errors were found to be the most common in Jordan.

By the descriptive analysis of the collected data about lapses in driving, and calculating the measures of central tendency, the most common answer for the frequency of people realizing that they have no clear recollection of the road they have been travelling along was that they occasionally realized that, which shows that this is not a very common lapse. Also, drivers said that they occasionally forget the place they have parked their car in due to lack of concentration.

Table 6 and 7 show the DBQ mean scores and standard deviations for each of the individual items related to violations, errors and lapses among Jordanian drivers. In these tables the mean represents the following: 0 - never, 1 - hardly ever, 2 occasionally, 3 - quite often, 4 - frequently, 5 - nearly all the time. 
Table 6. Means and Standard deviations of items of Driver Behavior Questionnaire $(D B Q)$ part 1

\begin{tabular}{|c|c|c|}
\hline Variables & Mean & $\begin{array}{c}\text { St. } \\
\text { deviation }\end{array}$ \\
\hline \multicolumn{3}{|l|}{$\begin{array}{ll}\text { Violations } \\
\end{array}$} \\
\hline Disregard the speed limits late at night or early in the morning & 2.18 & 1.76 \\
\hline Disregard the speed limits on a motorway & 2.13 & 1.67 \\
\hline $\begin{array}{l}\text { Become impatient with a slow driver in the outer lane and } \\
\text { overtake on the inside (right) lane }\end{array}$ & 2.13 & 1.50 \\
\hline $\begin{array}{l}\text { Sound your horn to indicate your annoyance to another road } \\
\text { user }\end{array}$ & 2.02 & 1.45 \\
\hline $\begin{array}{l}\text { Stay in a motorway lane that you know will be closed ahead } \\
\text { until the last minute before forcing your way into the other } \\
\text { lane }\end{array}$ & 1.94 & 1.67 \\
\hline $\begin{array}{l}\text { Drive especially close to the car in front as a signal to its driver } \\
\text { to go faster or get out of the way }\end{array}$ & 1.91 & 1.69 \\
\hline $\begin{array}{l}\text { Have an aversion to a particular class of road user and indicate } \\
\text { your hostility by whatever means you can }\end{array}$ & 1.59 & 1.48 \\
\hline $\begin{array}{l}\text { Angered by another driver's behavior, you give chase with the } \\
\text { intention of giving him/her a piece of your mind }\end{array}$ & 1.13 & 1.17 \\
\hline Get involved with unofficial 'races' with other drivers & 0.86 & 1.13 \\
\hline Crossing a red light & 0.75 & 0.99 \\
\hline \multicolumn{3}{|l|}{$\begin{array}{ll}\text { Errors } \\
\end{array}$} \\
\hline $\begin{array}{l}\text { Attempt to overtake someone that you hadn't noticed to be } \\
\text { signaling a left turn }\end{array}$ & 1.40 & 1.32 \\
\hline $\begin{array}{l}\text { Fail to check your rear-view mirror before pulling out or } \\
\text { changing lanes, etc. }\end{array}$ & 1.22 & 1.34 \\
\hline $\begin{array}{l}\text { Underestimate the speed of an oncoming vehicle when } \\
\text { overtaking }\end{array}$ & 1.14 & 0.98 \\
\hline $\begin{array}{l}\text { Miss ‘Give Way’ signs and narrowly avoid colliding with } \\
\text { traffic having right of way }\end{array}$ & 1.06 & 1.13 \\
\hline $\begin{array}{l}\text { Apply sudden brakes on a slippery road, or steer wrong way in } \\
\text { a skid }\end{array}$ & 0.96 & 0.87 \\
\hline $\begin{array}{l}\text { Queuing to turn right onto a main road, you pay close attention } \\
\text { to the mainstream of traffic that you nearly hit the car in front }\end{array}$ & 0.92 & 1.14 \\
\hline $\begin{array}{l}\text { Fail to notice that pedestrians are crossing when turning into a } \\
\text { side street from a main road }\end{array}$ & 0.79 & 0.94 \\
\hline $\begin{array}{l}\text { On turning right nearly hit a two-wheeler who has come up on } \\
\text { your inside }\end{array}$ & 0.69 & 0.88 \\
\hline
\end{tabular}


Table 7. Means and Standard deviations of items of Driver Behavior Questionnaire $(D B Q)$ part 2

\begin{tabular}{|c|c|c|}
\hline Variables & Mean & $\begin{array}{c}\text { St. } \\
\text { deviation }\end{array}$ \\
\hline \multicolumn{3}{|l|}{ Lapses } \\
\hline Attempt to drive away from the traffic lights & 3.47 & 1.47 \\
\hline $\begin{array}{l}\text { Realize you have no clear recollection of the road along } \\
\text { which you have been travelling }\end{array}$ & 1.75 & 1.34 \\
\hline Forget where you left your car in the car park & 1.50 & 1.31 \\
\hline $\begin{array}{l}\text { Get into the wrong lane when approaching a roundabout or } \\
\text { a junction }\end{array}$ & 1.43 & 1.09 \\
\hline $\begin{array}{l}\text { Intending to drive to destination A and, you 'wake up' to } \\
\text { find yourself in destination B, because the latter is your } \\
\text { more usual destination }\end{array}$ & 1.43 & 1.15 \\
\hline $\begin{array}{l}\text { Hit something when reversing that you had not previously } \\
\text { seen }\end{array}$ & 1.31 & 0.99 \\
\hline $\begin{array}{l}\text { Switch on one thing, such as headlights, when you meant to } \\
\text { switch on something else, such as wipers }\end{array}$ & 1.21 & 1.10 \\
\hline $\begin{array}{l}\text { Misread the signs and exit from the roundabout on the } \\
\text { wrong road }\end{array}$ & 1.10 & 0.99 \\
\hline
\end{tabular}

\subsection{Strong and weak driving components}

The participants were asked to describe the strength of the components of their driving style. Table 8 shows the results where $77.6 \%$ of drivers claim that they are careful drivers, while $81.3 \%$ of them can react fast in critical situations, and $79.1 \%$ show consideration for other road users, $87.4 \%$ have full control over the vehicle in normal conditions.

Secondly, when it came to the weak components, it was found that $42.6 \%$ of the respondents lose their patience when driving behind a slow car, and $29.1 \%$ of the recorded sample can't tolerate other driver errors calmly. This indicates that drivers are usually short-tempered. Yet $22.4 \%$ of drivers face difficulties in driving within the speed limits.

Moreover, controlling the car through a skid, fluent lane changing in heavy traffic, and reverse parking in narrow gap scored a weak performance, with a percentage of $20.2 \%$ of the recorded sample. 
Table 8. Strong and weak components in driving style

\begin{tabular}{|c|c|c|c|c|c|}
\hline & $\begin{array}{l}\text { Definitely } \\
\text { Strong }\end{array}$ & Strong & $\begin{array}{c}\text { Neither } \\
\text { weak } \\
\text { nor } \\
\text { strong }\end{array}$ & Weak & $\begin{array}{l}\text { Definitely } \\
\text { Weak }\end{array}$ \\
\hline $\begin{array}{l}\text { Performance in a critical } \\
\text { situation }\end{array}$ & $21.6 \%$ & $41 \%$ & $26.1 \%$ & $7.5 \%$ & $3.7 \%$ \\
\hline $\begin{array}{l}\text { Driving behind a slow car } \\
\text { without getting impatient }\end{array}$ & $6 \%$ & $25.4 \%$ & $26.1 \%$ & $23.9 \%$ & $18.7 \%$ \\
\hline $\begin{array}{l}\text { Managing the car through a } \\
\text { skid }\end{array}$ & $11.2 \%$ & $38.1 \%$ & $30.6 \%$ & $14.9 \%$ & $5.2 \%$ \\
\hline $\begin{array}{l}\text { Predicting traffic situations } \\
\text { ahead }\end{array}$ & $16.4 \%$ & $53 \%$ & $19.4 \%$ & $8.2 \%$ & $3 \%$ \\
\hline Driving carefully & $24.6 \%$ & $53 \%$ & $14.9 \%$ & $6 \%$ & $1.5 \%$ \\
\hline $\begin{array}{l}\text { Knowing how to act in } \\
\text { particular traffic situations }\end{array}$ & $14.9 \%$ & $53 \%$ & $24.6 \%$ & $7.5 \%$ & $0 \%$ \\
\hline $\begin{array}{l}\text { Fluent lane changing in heavy } \\
\text { traffic }\end{array}$ & $14.9 \%$ & $44 \%$ & $20.8 \%$ & $16.4 \%$ & $3.7 \%$ \\
\hline Fast reactions & $23.1 \%$ & $58.2 \%$ & $14.9 \%$ & $3 \%$ & $0.7 \%$ \\
\hline $\begin{array}{l}\text { Showing consideration for } \\
\text { other road users }\end{array}$ & $25.4 \%$ & $53.7 \%$ & $12.7 \%$ & $6 \%$ & $2.2 \%$ \\
\hline $\begin{array}{l}\text { Staying calm in irritating } \\
\text { situations }\end{array}$ & $7.5 \%$ & $23.9 \%$ & $33.6 \%$ & $20.9 \%$ & $14.2 \%$ \\
\hline Controlling the vehicle & $29.9 \%$ & $57.5 \%$ & $9.7 \%$ & $2.2 \%$ & $0.7 \%$ \\
\hline $\begin{array}{lll}\text { Avoiding } & \text { competition in } \\
\text { traffic }\end{array}$ & $35.8 \%$ & $34.3 \%$ & $11.9 \%$ & $7.5 \%$ & $10.4 \%$ \\
\hline $\begin{array}{l}\text { Keeping a } \quad \text { sufficient } \\
\text { following distance }\end{array}$ & $20.9 \%$ & $38.1 \%$ & $23.8 \%$ & $10.4 \%$ & $6.7 \%$ \\
\hline Overtaking & $23.9 \%$ & $39.6 \%$ & $23.9 \%$ & $9 \%$ & $3.7 \%$ \\
\hline $\begin{array}{l}\text { Relinquishing legitimate } \\
\text { rights when necessary }\end{array}$ & $12.7 \%$ & $41.8 \%$ & $25.4 \%$ & $16.4 \%$ & $3.7 \%$ \\
\hline $\begin{array}{l}\text { Confronting to the speed } \\
\text { limits }\end{array}$ & $15.7 \%$ & $37.3 \%$ & $24.6 \%$ & $18.7 \%$ & $3.7 \%$ \\
\hline Avoiding unnecessary risks & $27.6 \%$ & $44 \%$ & $14.1 \%$ & $9.7 \%$ & $4.5 \%$ \\
\hline $\begin{array}{l}\text { Tolerating other drivers' } \\
\text { errors calmly }\end{array}$ & $6.7 \%$ & $32.8 \%$ & $31.4 \%$ & $20.1 \%$ & $9 \%$ \\
\hline $\begin{array}{l}\text { Reverse parking in a narrow } \\
\text { gap }\end{array}$ & $27.6 \%$ & $37.3 \%$ & $14.9 \%$ & $7.5 \%$ & $12.7 \%$ \\
\hline
\end{tabular}




\section{Road safety campaigns awareness in Jordan}

People awareness of road safety campaigns in Jordan was investigated during the data collection phase. Analysis of the responses revealed the followings:

People who are aware of road safety campaigns constitute only $14.9 \%$ of drivers with only $12.7 \%$ of them believe that the campaigns are effective.

1) The most popular mediums for road safety campaigns are the internet and radio as reported by $23.9 \%$ of the responses followed by internet and TV $(17.9 \%)$.

2) The most effective traffic enforcement tools are presented in figure 2 ,

- $\quad$ Speed cameras (as reported by $36 \%$ )

- Police presence $(25 \%)$

- $\quad$ Traffic light cameras $(21 \%)$

- Others $(18 \%)$

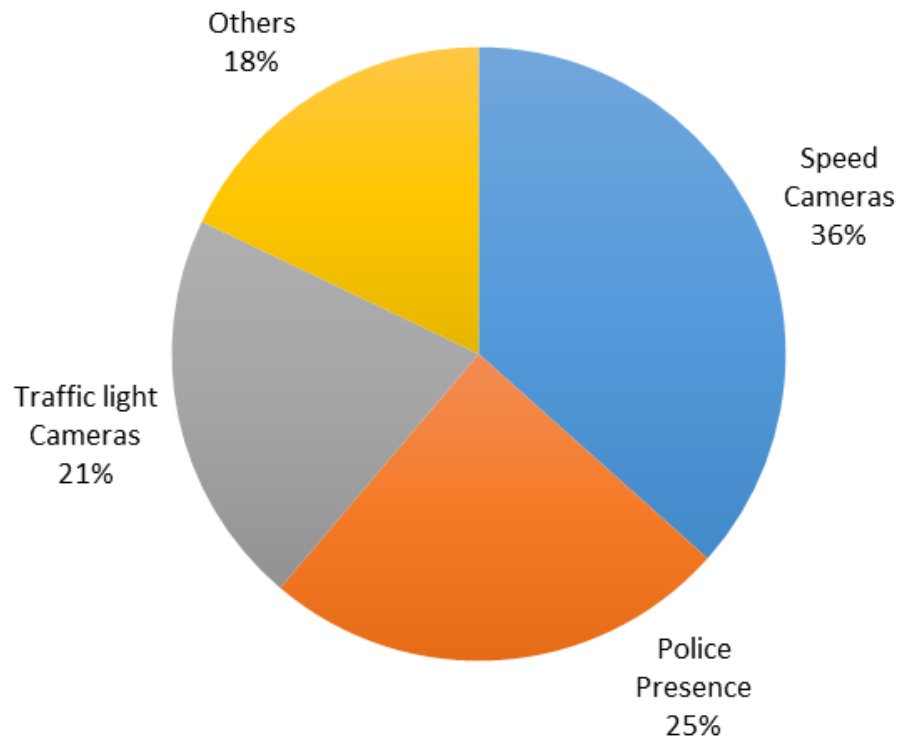

Figure 2. Most effective traffic enforcement tools 
3) Drivers who think that speeding fines must be raised constitute $29.9 \%$ of the total participants whereas $70.1 \%$ think that speeding fines are high enough.

4) Drivers who think that there should be an increased police presence at main junctions constitute $(56 \%)$ of drivers.

5) Drivers who think that more road safety strategies should be implemented $(85.8 \%)$.

6) Drivers who think that high powered cars should have speed restricting devices $(71.6 \%)$.

7) Drivers who think that should be a special hotline to report aggressive drivers $(90.3 \%)$.

8) Drivers who think that mobile radars should be used during peak volume traffic $(58.2 \%)$.

9) Drivers who think all high peak roundabouts should be equipped with traffic lights (55.2\%). A remarkable decrease in traffic congestion at two of the high peak roundabouts in Amman city was detected after this solution was implemented in 2019.

\section{Drivers' suggestions}

The participants reported some suggestions that they perceive effective in reducing the magnitude of road safety problem in Jordan. These include: regular maintenance of roads, filling holes in streets and regularly renewing street markings, and providing proper street lighting.

Another field that the drivers feel requires improvement is the use of traffic calming techniques. They suggested that more humps should be installed to reduce drivers' speed, while providing road signs and adding more posted speed signs will force drivers to abide with traffic laws and regulations. Effective enforcement of traffic law was also perceived as another intervention with potential for accident reduction in Jordan.

\section{Methodological limitations}

Although several studies have reported that self-reports of driving may correspond well to actual driving behavior, the collected data used for the purpose of this study were based mostly on drivers' self- reported behavior and no observations were made. It is also possible that some respondents could mislead their answers about positive and aggressive driving. Furthermore, the measurements of accidents and 
injuries involvement were based on a self-report of all accidents. Therefore, some respondents may have underestimated the number of accidents in which they had been involved.

\section{Conclusion}

The following conclusions were drawn based on the results of data analysis and evaluation conducted in this study.

- Jordanian drivers who have longer driving experience tend to be involved in higher cumulative number of traffic accidents through their driving years; the reason behind this is their longer years of exposure, therefore it is very likely that they have been involved in more accidents.

- It was proven that careless driving is the most common self-reported reason behind traffic accidents with $46.5 \%$ of the participating drivers supporting this view.

- The most common traffic violation practiced is speeding, 34\% of drivers disregard the speed limits especially late at night and early in the morning. (hence that there are no motorways in Amman).

- The most common errors reported by drivers were found to be; failing to check rear mirror before pulling out or changing lanes, and under-estimating the speed of an oncoming vehicle in overtaking.

- Regarding lapses, $27.6 \%$ of drivers showed that they have no clear recollection of the road they have been travelling along, and this is not a highly common lapse. However, $26.1 \%$ usually forget where they parked their car in due to lack of concentration.

- The strong components of the driving style of Jordanian drivers were found to be their claim being careful drivers $(77.60 \%)$, while $81.30 \%$ of them reported that they can react fast in critical situations.

- Internet and radio media forms are the most effective in delivering traffic awareness campaigns to drivers.

- Traffic enforcement tools such as speed cameras and police presence, are the most effective in regulating driver's aberrant behavior.

\section{Recommendations}

Considering the burden and impact of traffic accidents in Amman, more road safety campaigns should be launched, initiated, and supported, yet strategic road 
safety management mechanisms should be developed and implemented to control and reduce the growing accidents rate.

Driver behavior questionnaire is an effective tool in this process since the results found in this study can be used as a reference in further studies. However, it is highly recommended to conduct this survey online, since face to face interviews consumed lots of time, and this is guaranteed to reach a larger sample of drivers in order to result in more representative results, identify outliers and provide a smaller margin of error.

\section{References}

[1] Zs. Sándor, A. Monostori, Traffic Analysis of Specific Motorways with Different Usage Characteristics in Hungary with the Method of Section Control, Acta Technica Jaurinensis 13 (3) (2020) pp. 211-245.

doi: https://doi.org/10.14513/actatechjaur.v13.n3.554

[2] A. Kizawi, A. Borsos, A literature review on theconflict analysisof vehiclepedestrian interactions, Acta Technica Jaurinensis (2021).

doi: https://doi.org/10.14513/actatechjaur.00601

[3] A. Bener, T. Özkan, et al., The Impact of Aggressive Behaviour, Sleeping, and Fatigue on Road Traffic Crashes as Comparison between Minibus/Van/Pick-up and Commercial Taxi Drivers, Journal of Traffic and Transportation Engineering 5 (2017) pp. 21-31.

doi: https://doi.org//10.17265/2328-2142/2017.01.003

[4] A. Bener, D. Crundall, Role of gender and driver behaviour in road traffic crashes, International Journal of Crashworthiness 13 (3) (2008) pp. 331-336. doi: https://doi.org//10.1080/13588260801942684

[5] K. Jadaan, A. Bener, E. Braizat, Formulation of road safety strategy for developing countries with special reference to Jordan, Advances in Transportation Studies an International Journal 40 (2016) pp. 101-111. doi: https://doi.org/10.4399/97888548970078

[6] A. Bener, K. Jadaan, et al., The effect of aggressive driver behavior, violation and error on vehicle crashes involvement in Jordan, International Journal of Crashworthiness 25 (3) (2019) pp. 276-283.

doi: https://doi.org//10.1080/13588265.2019.1583422 
[7] J.C.F. de Winter, D. Dodou, The driver behaviour questionnaire as a predictor of accidents: A meta-analysis, Journal Safety Research 41 (6) (2010) pp. 463-470.

doi: https://doi.org//10.1016/j.jsr.2010.10.007

[8] N. Zhao, B. Mehler, et al., An investigation of the relationship between the driving behavior questionnaire and objective measures of highway driving, Transportation Research Part F: Traffic Psychology and Behaviour 15 (6) (2012) pp. 676-685.

doi: https://doi.org//10.1016/j.trf.2012.08.001

[9] A. Kashani, M. Ravasani, E. Ayazi, Analysis of Drivers' Behavior using Manchester Driver Behavior Questionnaire Based on Roadside Interview in Iran, International Journal of transportation Engineering 4 (1) (2016) pp. 6174.

doi: https://doi.org//10.22119/IJTE.2016.33497

[10] A. Bener, E. Yildirim, et al., The Driver Behavior Questionnaire as an accident predictor in Cross-cultural Countries in Qatar and Turkey: Global Public Health Problem, British Journal of Medicine and Medical Research 15 (7) (2016) pp. 1-9.

doi: https://doi.org//10.9734/BJMMR/2016/25719

[11] D. Parker, L. McDonald, et al., Elderly drivers and their accidents: The aging driver questionnaire, Accident Analysis and Prevention 32 (6) (2000) pp. 751-759.

doi: https://doi.org//10.1016/S0001-4575(99)00125-6 